\title{
Bone Chondroblastoma in Children: About Case and Review the Literature
}

\author{
S. Bezzanin*, A. Dendan, A. Amrani, T. Madhi
}

Department of Pediatric Orthopedic Surgery, Children's Hospital, Rabat, Morocco

DOI: $10.36347 /$ sasjs.2020.v06i07.003

| Received: 08.06.2020 | Accepted: 17.06.2020 | Published: 11.07.2020

*Corresponding author: Sabra Bezzanin

Abstract

Case Report

Chondroblastoma is a primary bone tumor in children, adolescents and young adults, which accounts for $1 \%$ of all bone tumors. Epiphyseal or epiphysometaphyseal localization, this lesion usually develops from secondary ossification centers close to the knee, shoulder and hip. In our work we will report an original of a knee chondroblastoma in a 13year-old girl with difficulties in surgical decision-making.

Keywords: Chondroblastoma, adolescents, bone tumors, Epiphyseal.

Copyright @ 2020: This is an open-access article distributed under the terms of the Creative Commons Attribution license which permits unrestricted use, distribution, and reproduction in any medium for non-commercial use (NonCommercial, or CC-BY-NC) provided the original author and source are credited.

\section{INTRODUCTION}

Chondroblastoma is a rare, benign cartilaginous tumor, developed in an epiphysis or an apophysis, near the growth cartilage (young subject); sometimes it is calcified. A few cases are described in adolescents. In our work we will report an original of a knee chondroblastoma in a 13-year-old girl with difficulties in surgical decision-making.

\section{Patient and Observation}

We report the clinical case of a 13-year-old girl who presented with a chronic joint blockage in the right knee. The revealing clinical symptomatology was an intermittent and painless joint blockage in the right knee, evolving for 2 months. The clinical examination revealed a meniscal syndrome with a positive meniscal test (Mc Murray, Thesaly ...). Standard radiography: Postero-external lesion of the proximal tibia (image of osteolysis) (Fig-1). CT: Epiphyso-metaphyseal tumor with probable articular rupture (Fig-2). The biopsy: bone chondroblastoma (Fig-3). The therapeutic procedure consisted in broad intra lesional curettage by antero-external route with a massive spongy graft. The postoperative follow-ups were simple with consolidation in 4 months (Fig-4) and complete disappearance of symptoms at 6 months.

After a 24-month follow-up, no recurrences were noted (Fig-5).
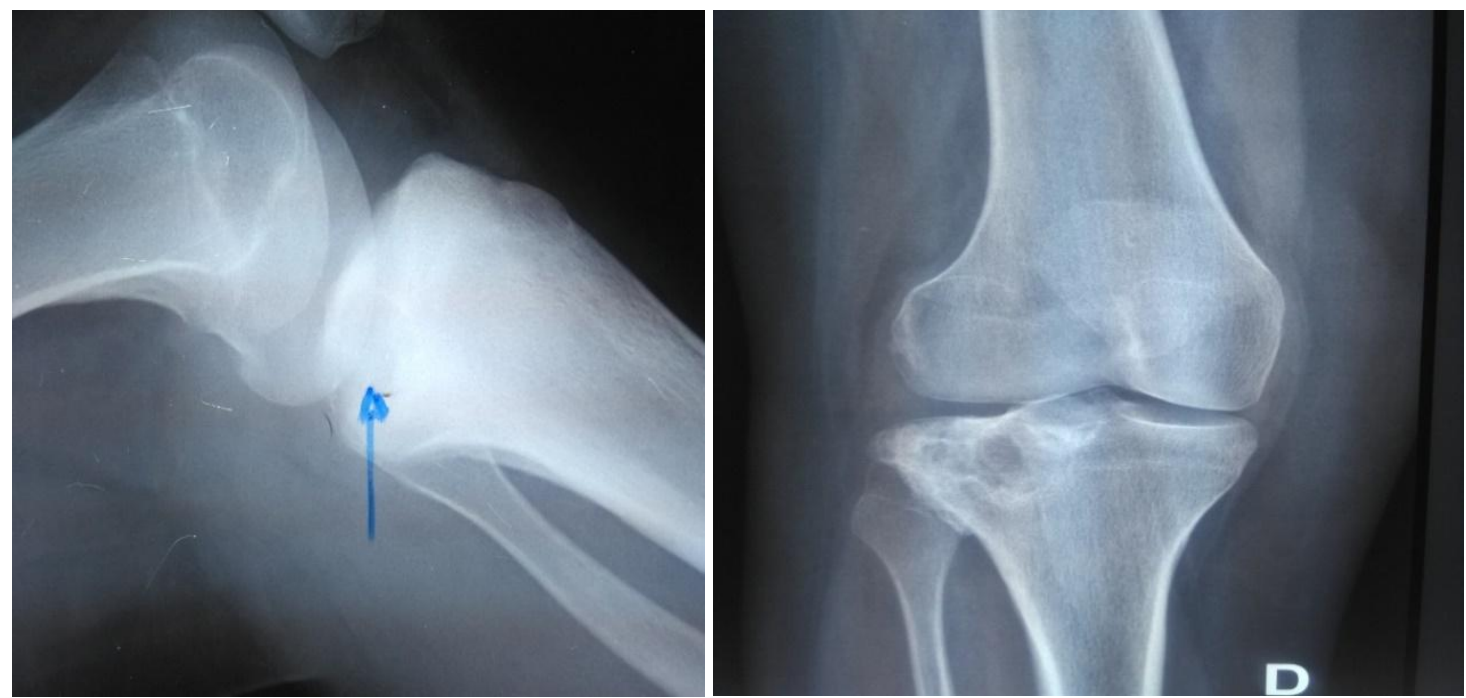

Fig-1: Postero-external lesion of the proximal tibia (image of osteolysis) 


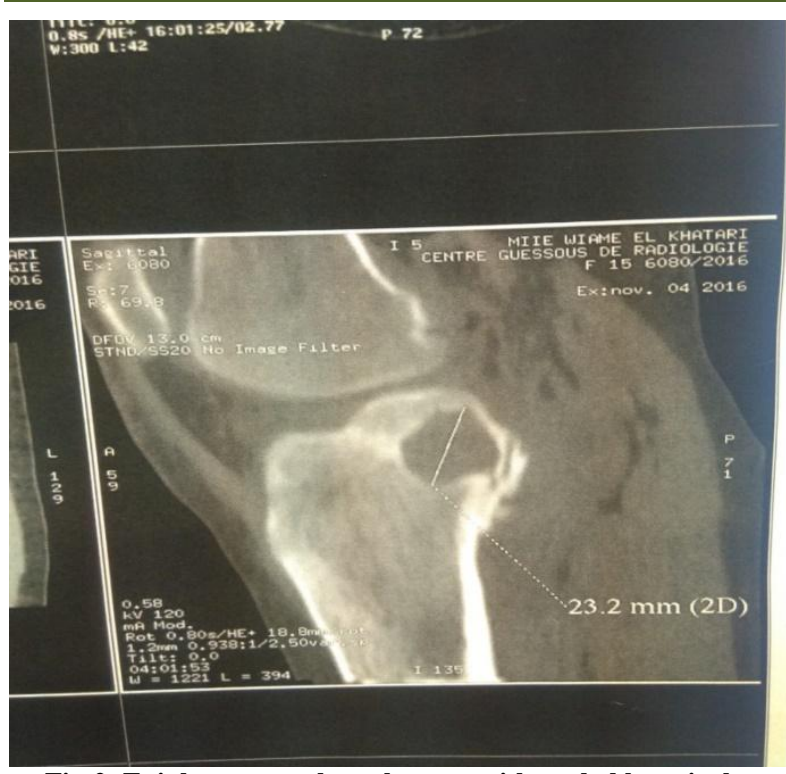

Fig-2: Epiphyso-metaphyseal tumor with probable articular rupture

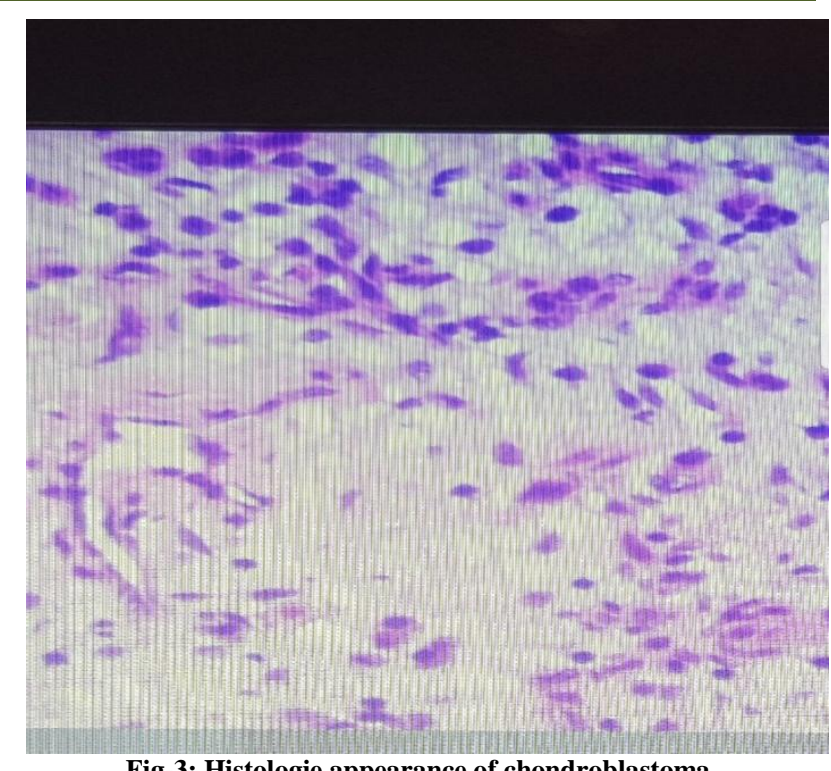

Fig-3: Histologie appearance of chondroblastoma

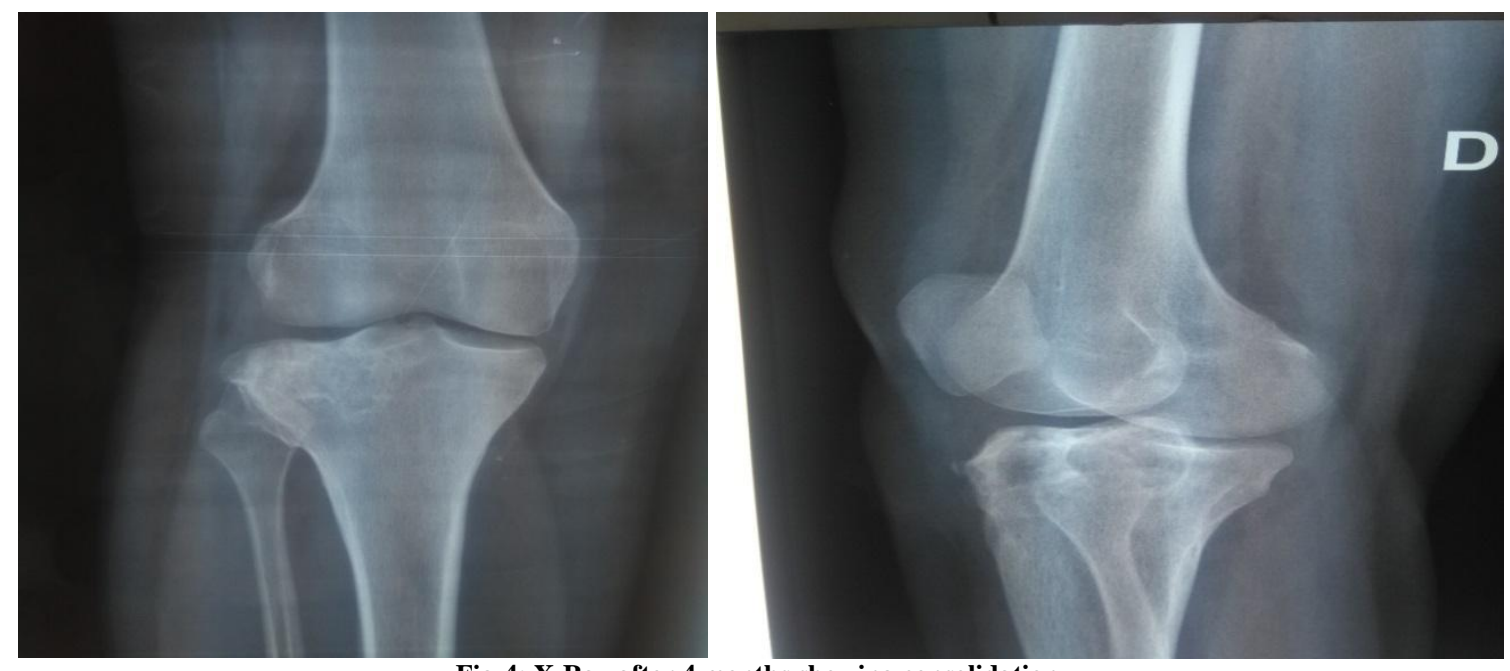

Fig-4: X-Ray after 4 months showing consolidation.
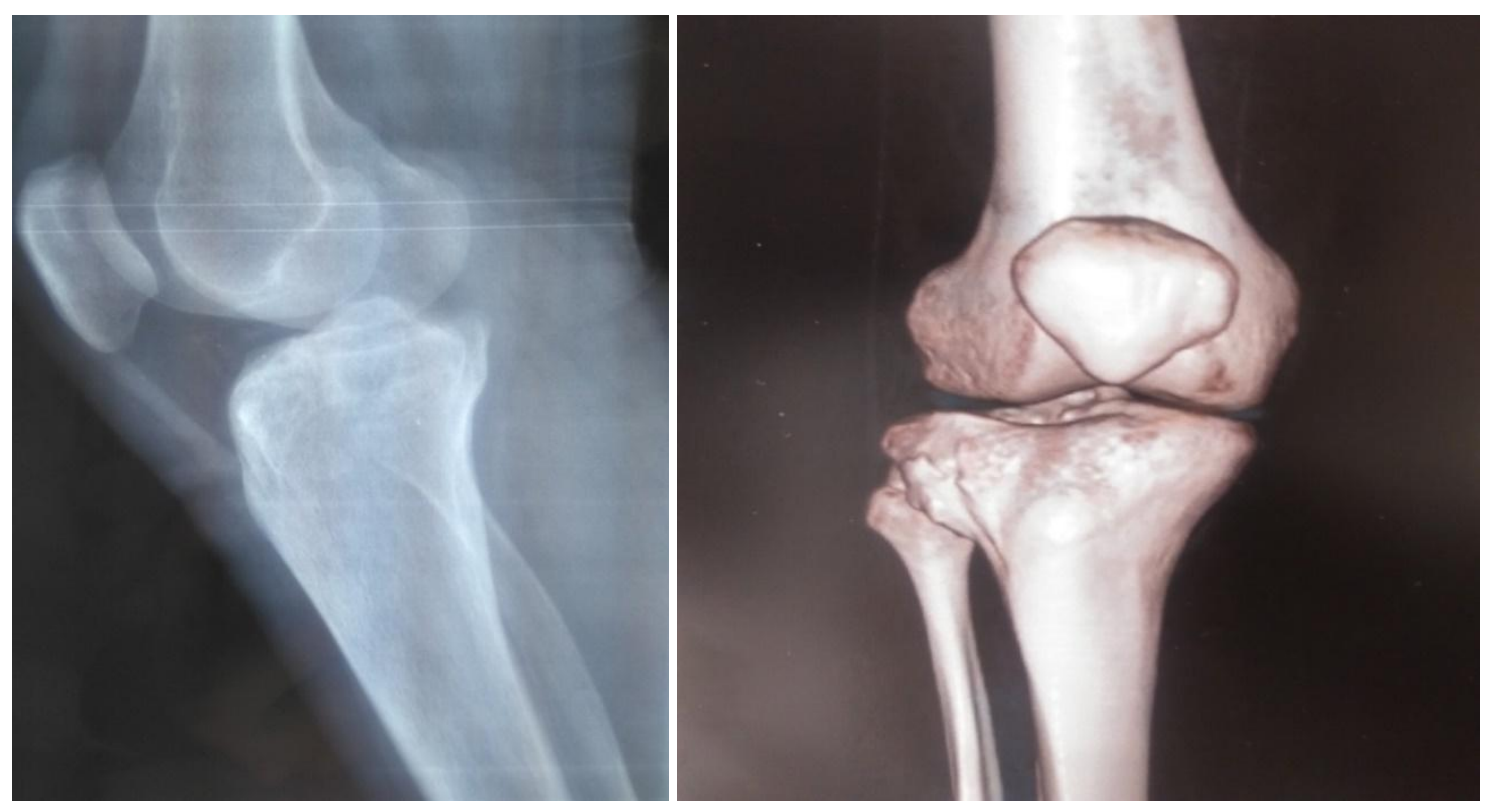

Fig-5: No recurrence after 6 months 


\section{DISCUSSION}

Chondroblastoma $(\mathrm{CB})$ is a very rare benign cartilage tumor in adolescents, the first symptom is often pain, lameness; sometimes it is revealed by local swelling; It mainly affects the pure epiphyses, sometimes it is of epiphyso-metaphyseal or pure metaphyseal site [1].

Radiologically the lesion is described as a geographic osteolysis with a dense peripheral border at the level of the epiphysis (standard radiography); namely multiple gaps with intra-lesional calcifications in rings (computed tomography) [2].

There are three surgical approaches: anterolateral, posterior popliteal or arthroscopic; the definitive treatment consists of curettage of the tumor with filling by autograft or with cement, sometimes a mosaicoplasty [3].

Histological analysis may reveal an associated aneurysmal component. The $\mathrm{S} 100$ protein is often positive; except that it never reveals signs of malignancy or cellular atypia [4].

The evolutionary profile of chondroblastoma is variable: joint stiffness or growth disorder; recurrences after surgical treatment are possible [5].

\section{CONCLUSION}

Chondroblastoma remains a benign, metaphysoepiphyseal or epiphyseal tumor of long bones, infrequent (1\% of primary bone tumors), occurring between 5-25 years with a male prevalence and a high rate of recurrences.

\section{REFERENCE}

1. Kilpatrick SE, Parisien M, Bridge JA. Chondroblastoma. In: Fletcher CDM, Unni KK, Mertens F, editors. World Health Organization classification of tumors. Pathology and genetics of tumours of soft tissue and bone. Lyon: IARC Press; 2002. p. 241-2

2. Railhac JJ. Imagerie des tumeurs osseuses. Montpellier: Sauramps Médical; 1999

3. Suneja R, Grimer RJ, Belthur M, Jeys L, Carter SR, Tillman RM, Davies AM. Chondroblastoma of bone: long-term results and functional outcome after intralesional curettage. The Journal of bone and joint surgery. British volume. 2005 Jul;87(7):974-8.

4. Resnick D, Kransdorf MJ. Bone and joint imaging. Philadelphia: Elsevier Saunders; 2004.

5. Weatherall PT, Maale GE, Mendelsohn DB, Sherry CS, Erdman WE, Pascoe HR. Chondroblastomes: classic and confusing appearance at MR imaging. Radiology, 1994;190: $467 \mathrm{e} 7$. 